International Research Journal of Management, IT \& Social Sciences
Available online at https://sloap.org/journals/index.php/irjmis/
Vol. 7 No. 3, May 2020, pages: 50-57
ISSN: 2395-7492
https://doi.org/10.21744/irjmis.v7n3.890

\title{
Contemporaneous Theory in Education
}

\author{
María Gabriela Bravo Vélez ${ }^{a}$ \\ Elsa María Figueroa Sandoval
}

\section{Article history:}

Submitted: 09 January 2020

Revised: 18 February 2020

Accepted: 27 March 2020

\section{Keywords:}

contemporary theories; educational paradigms; learning-teaching; modern school; pedagogical;

\begin{abstract}
The research contextually supports content focused on contemporary theories in the educational field and in which it presents the path of evolution in humanity, based on the learnings that have had to undergo it since the human being in its adaptation has allowed there to be a prospect to the educational advancement. The goal of research is to analyze the changes necessary for the creation and adaptation of learning to understand the development that learning has had in modern school. The bibliographic review and synthetic analytical method were used as a technique, to know contemporary theories and the influence they have on the learning-teaching process in education, it was obtained as a result that learning contemporary theories, fused to the modern school allow the expansion of knowledge by adapting techniques and strategies in students, in Ecuador has been involved the application of these, to develop new and diverse pedagogical processes, proposes training to teachers in new techniques to improve cognitive abilities.
\end{abstract}

International research journal of management, IT and social sciences (C) 2020. This is an open access article under the CC BY-NC-ND license (https://creativecommons.org/licenses/by-nc-nd/4.0/).

\section{Corresponding author:}

Elsa María Figueroa Sandoval,

Maestría en Innovación en Educación,

Pontificia Universidad Católica del Ecuador, sede Manabí, Chone, Ecuador.

Email address: mbravo5261@pucem.edu.ec

a Pontificia Universidad Católica del Ecuador, sede Manabí, Chone, Ecuador

Pontificia Universidad Católica del Ecuador, sede Manabí, Chone, Ecuador 


\section{Introduction}

Contemporary theories, in the educational field, allow intensifying the analytical potential and behavior of each individual, in his study the psychology has sought to locate the rise of knowledge in the human being, over the years one of the most outstanding tasks of man has undoubtedly been the strengthening of learning capacities, applying new theories and experiencing various ways of interpreting them. These and application of learning concepts has allowed measuring results for the benefit of its improvement, because of this the National Technical-Pedagogical Council (CNTP), (Diaz, 2013) defines it as the set of knowledge that an individual possesses in a certain field of knowledge. When these existing knowledge related to new information, not in a sum of concepts, but an interactive link, learning is generated.

Educational Theories are conceptual frameworks based on research, which have served to describe, explain and guide the educational work, as well as to build and reconstruct knowledge of it, refer to a social fact developed around the person when the human being understands the potential that contemporary theories maintain, may be able to limit those problems that have produced chaos in various areas of study (Guzmán \& Martínez, 2018). In the field of educational research, the attitude of the methodological flexibility of the researcher is key to the understanding of the phenomenon under study, because because of its education has managed to give great changes (Cantero, 2013). The more education actors get involved with research, the better the teaching practice.

Research in the use and application of learning concepts has allowed measuring results for the benefit of learning, for this cetacean the conceptual frameworks educative theories that serve for an explanation, guidance, to describe in all educational aspects, also to build knowledge. When humans understand the potential of contemporary theories, they may be able to limit those problems that have caused chaos in various areas of study. Contemporary theories are immersed in various day-to-day activities, including in past decades as a fundamental part of the series of accelerated changes and learning management in the world, today those who are oblivious to the use of theories in the pro-learning development tend to lose opportunities to overcome and express a declining culture in intellectual preparation.

As a positive approach, modern educational hypotheses have given a great evolutionary breakthrough, for teachers and staff working transforming education, the implementation of these theories underpin their teaching process, knowing the techniques that must be implemented within the classrooms, some of them are that of Learning by Discovery, Of Meaningful Learning, Cognitivism, Conductivism, Constructivism, Socio-constructivism and Information Processing. The information process is inherent in the use of technologies in the modern era, as digital applications have made everyday life easier on a large scale, from the simple fact of posting a comment on some social network to the countless heyday of commercial and banking transactions, but not everything seems to be productive in this digital contemporary era the study to sedentarism is marked mainly by the improper abuse of the same digital tools, but which correctly implemented can contribute to social development (Suryasa et al., 2020).

The research is based on analyzing the changes needed to create a complete learning adaptation, which mentions modern techniques that set guidelines for the development of education. The correct application of these strategies in education is not an easy task, you need to maintain knowledge in the area of psychology, to be able to interpret patterns of development to the knowledge that students acquire and produce, contemporary theories as a tool, is a science enhanced over several decades, with leaps and bounds, present in all areas of work and studies for humanity, in the social terms computing is applied in creating an awareness of realities giving way to new forms of the trend in learning, expanding group knowledge in different aspects.

The teacher and the student must reach the awareness, dialogue and critical reflection that flows from the very plot of daily life (Villalobos, 2000). Theories allow to analyze the scope that education has had in humanity, but it cannot be ruled out that, at present, education depends not only on theories but also, to the daily life of each student, in some cases leads the teacher to look for strategies and techniques that achieve meaningful learning in it such as the implementation of video games as a tool in the learning processes (Meneses et al., 2020). Philosophy is a strategy to support the mass media responsible for expanding learning, thus reaching a new phase which consists in interpreting the greatest amount of knowledge, working in conjunction with new learning theories will maintain improved visions of quality education, comprehensive and able to foster working relationships when it is known that the main task of an educator is to motivate meaningful learning, comprehensive reading and knowledge creation in its students, which can be ventured with projects based on learning strategies (Lopez et al., 2020). These projects can be implemented from valvular ages so that children from a young age can acquire knowledge through different methods developed by teachers' docents (Mero et al., 2020).

Vélez, M. G. B., \& Sandoval, E. M. F. (2020). Contemporaneous theory in education. International Research Journal of Management, IT and Social Sciences, 7(3), 50-57. https://doi.org/10.21744/irjmis.v7n3.890 


\section{Materials and Methods}

The applied methodology is bibliographic and theoretical research - synthetic analysis, in which the different types of learning paradigms and their functional analysis are conceptualized. Focusing on the changes that education and humanity have given. This research proposes the interpretation of bibliographic information, leading to the reflection of the importance of the evolution of education, its approaches, and paradigms since this will be able to analyze the changes that the teaching-learning process has had over time.

\section{Results and Discussions}

\subsection{Theories of learning in education}

On the evolutionary path, the human being has been able to adapt to different living conditions, either by supremacy or survival all those tools of the solution to existing problems have been able to be mastered with the habit and intelligence of each being, according to (Rodriguez, 2016). Learning to the path of encounters has animated different opinions during study history. Also, a boom that explains that the reasoning of such matters has given the necessary mechanisms to provide pedagogy, psychology, among other sciences. In context, there is the ability to analyze learning as an experience that allows you to automate everyday problems and simplify work.

Knowing the basic needs of the human being are identified: food, clothing, housing, health, and as complementary elements include safety, communication, transport, work, sports, leisure. It is notorious that for any activity that involves a need. The contemporary theories provide support in the optimization of resources to information and time, seen by some authors such as (Dominguez, 2008), contributions in a comprehensive way from the direction of the human resources are established policies that contribute to improvements in technology and increases in innovation in companies in the services sector that allow the optimization of information.

Currently thanks to the rise of these theories in education, the school becomes part of a significant step in the human being; knowing that education has constantly changed, it must be remembered that at first, the school was traditionalist based on visual information, of an exhibition of a teacher on any subject, where the student did not generate contributions or participate in the construction of knowledge, now it is about including in the process of teaching-learning the integration of students.

\subsection{The modern school in education}

The human being with his adapting ability has made it possible to focus digital tools on the development of education. The last decades cannot be set aside, changes in education are slower than in other processes and sectors of society, where significant changes have emerged, both in the reform of methods, content, teaching strategies and teaching resources, which the teacher has had to his provisions to develop his professional activity (Domínguez, 2014).

Strategic changes in education are always variants to the area of study since several years the work has been enhanced by various professions, however, it is clear that in educational terms the progress remains slight shortcomings in consideration of the time, several factors causing this problem can be exposed, one of which would be the little use and use of current theories, As far as technology is concerned, the changes in the development of tics that make it easier to assert that humans have been included in the society of knowledge have been noticed for several decades. The changes are present on different scales, but it is essential to note that those variations began to bear fruit and promote new ideas.

In modern school the development of learning is born internally based on individual gifts where it must be participatory, fostering with social work and experience is constituted by the experiment, in the methodology approach the modern index school in education through digital tools, planning, and adaptation to each form of the human being, Lto education is in a process that is distributed in diverse sciences and technologies, but always has an inherent technological imprint, its objective is to form and reproduce certain knowledge based on practices (Diaz, 2019; John et al., 2016). In context support, it is necessary to argue the importance of information technologies in the modern school, as it has been able to expand the knowledge with interactive work. 


\subsection{Paradigms in contemporary education}

When talking about education, activities should be linked that allow the complete and comprehensive analysis of the individual in education, what behavioral knowledge needs to be maintained help in the procedure. Figure 1 shows the Educational Paradigms and their classification (Tomozii \& Topală, 2014; Loncar et al., 2014).

When there is an acquired knowledge it is vital to understand the reasons and techniques that facilitated or complementary what acquired, according to Schunk (2012), a paradigm is not only an implicit commitment, not formulated or disseminated but also a reference framework on how the environment of a study community with a certain conceptual framework is observed, these points are part of categorical and critical elements in the field of educational psychology.

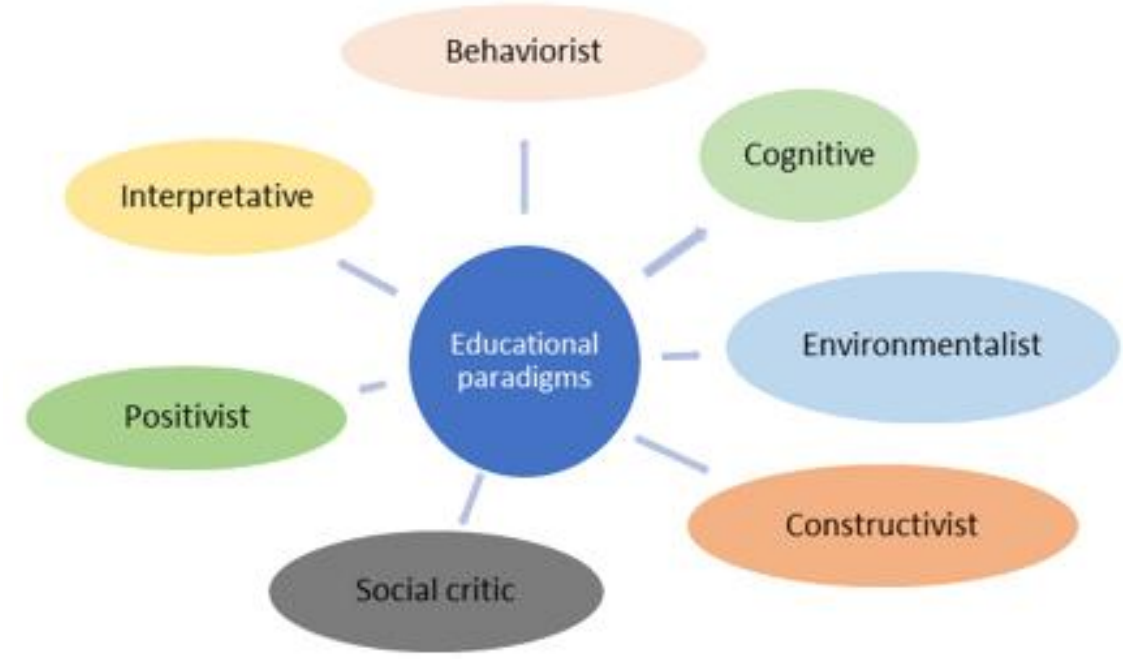

Figure 1. Educational paradigms and their classification Source: Andean Area University Foundation, 2017

Behavioral paradigm. The purpose of this paradigm is to be able to analyze the behavior of the individual, observe behaviors that can be categorized and segmented, for this (Trujillo, 2017) mentions that conduct arises as psychological theory and subsequently adapts its use in education. Its beginnings date back to the first decades of the twentieth century, the one who proposed it was Watson and the bases were given by Pavlov and Thorndike, and it is necessary to insinuate that every inner process such as thought, the motivation, the interest cannot be verified with observation sheets, therefore, are not relevant, it should be known that if there is no observable change in behavior there is no change in learning it is necessary to imply that each inner process such as thought, motivation, interest cannot be verified with observation sheets, therefore, are not relevant, it should be known that there is no change in learning. Behavioral Pedagogy develops didactics that allow the achievement of specific objectives whose purpose is to shape behavior according to social interests, thus establishing a great link between the role of society and education (Salas, 2007).

Cognitive paradigm. It is essentially based on the strength reached by the human being in teaching-learning in his approach to attention, memory the critical and logical analysis of his arguments, this paradigm allows a real vision of the human being since each being provides a different analysis of the environment (Fierro, 2011). In the educational principle of each student, we are given the guidelines to acquire and master knowledge, this theory of cognitivism expresses that the student continuously builds his learning what makes it possible to segment cognitive development into logical structures. From another approach the cognitive paradigm as opposed to behavioral stops categorizing the individual as an empty box, where the only thing that could be measured was the one that could be observed, it should be deepened that the learning of the individual is not limited only to what can be observed since internal thoughts, in general, are samples of acquired knowledge, in context cognitive psychology is based on the reconciliation of new knowledge through information processing and the search for meaning and awareness that affect learning.

Vélez, M. G. B., \& Sandoval, E. M. F. (2020). Contemporaneous theory in education. International Research Journal of Management, IT and Social Sciences, 7(3), 50-57. https://doi.org/10.21744/irjmis.v7n3.890 
Cognitive learning approaches involve a broad analysis of mental processes that, whether basic or genetic, which at the same time can be altered by external factors, contemporary theorists offer a more refined version of technique utensils for trying to interpret human thought.

Environmental paradigm. When analyzing environmentalist theorists, the complete study of the environment and its emphasis on learning should be considered, in this sense, the balanced knowledge and treatment of socio-natural environments are urgently needed, due to the accelerated degree of deterioration they are resisting, and the little importance that humanity is taking on it (Riera et al., 2009), education should be complemented by empirical development in theoretical-practical activities making analogies with the environment, research should be guided in pedagogical contributions by teachers in including the environment as a source of knowledge, it is clear that when one has a close relationship with the object of study it is easier to assimilate knowledge.

Constructivist paradigm. In the modern school without a doubt when referring to constructivist theorists is being talked about in the close relationship of the student with the teacher to create meaningful learning, the playful and recreational activities are part of the teaching process, therefore the material and training that teachers highlight are more marked in this paradigm. In concession with learning constructivism poses linear and systematic knowledge focused on each student and verify how their knowledge is structured through patterns differentiated to the rest, experiences also play a necessary role in these modern theories, In the pedagogical approach, this theory holds that Knowledge is not discovered, it is built: then the student raises his understanding from his internal interrelationship his thoughts and as he understands the world as he is committed to participating at every moment in your learning process (Tamir, 1988; Govindasamy, 2001; Shulman, 2000; Bailey \& Card, 2009; Kartal et al., 2012; Sanchez et al., 2019).

Critical-social paradigm. In the evaluation of education, the acceptance of students to be able to comment on their authorship to the criticality of a subject is relevant, it is not a question of questioning, valuing or disproving the positions of education on a particular subject, but, being able to reaffirm through dialogue the prior knowledge acquired. The acceptance work in modern schools has steadily advanced as teachers can include the participation of each student for the debate of the new classes, in the present moments, the argumentative works must be reinforced by critical thinking in the developer. The study of different perspectives in organizational models is the greatest interest to deepen knowledge of the evolution of teaching and school. The "socio-critical" theory is framed by "political" models.

Positivist paradigm. When referring to the impact of positivism in the educational field it should be mentioned that a different perspective of humans was being sought since the significant contribution in the construction of scientific knowledge is rooted in empirical work, it is also necessary to argue that the positivist paradigm has the desire to create strong people in opinions and thoughts, considering as real knowledge those that can be verified. Since he is a being capable of stripping away his feelings, emotions, subjectivity, in such a way that he can study the object, the social and human reality "from the outside". In positivism, it is considered that the researcher can be placed in a neutral position and that his values do not influence the results of his research (Martínez, 2015). This is why it can be said that positivism focuses on measuring results by experimenting with scientific methods to agree on complete learning.

Interpretative Paradigm. The investigative analysis is a revelatory part of human actions even more so in the social relationship when there is direct communication with subjects in the term education it is easier to interpret emotions, actions, descriptions, and ways of visualizing the environment. It is important to develop interpretation skills in qualitative and quantitative variables in teachers, more precisely in measuring the quality of actions. Overall contemporary theories in education complement each other, since the application of several of them, together, will make possible the partial and complete integration of meaningful learning.

\subsection{Research on contemporary pedagogical currents}

In the educational field, some paradigms are related to the study of the different situations of teaching-classroom learning and how individuals act in these forms. These paradigms are recognized as the trend for change in educational innovation, where teachers must be trained collaboratively and differences are $\mathrm{n}$ recognized, diversity and complexities of organic representations, which occur in the school which is where the learning-teaching processes are produced and 
re contextualized; they also defend the existence of technology (instruments and tools), from the energy dynamics of the curriculum as a decisive and fundamental gear for the development of culture since new technologies that have become primary tools in the teaching process - learning (Suarez, 2000; Ghasemi \& Hashemi, 2011; Hashemi \& Ghasemi, 2011).

In this respect, the role that the teacher has is to be critical and at the same time technical where the interactions develop, I generate a climate of trust and create expectations for the development of cognitive abilities. Given the current profuse pedagogical production, the shaping and delimitation of "contemporary pedagogical currents", it is urgent and essential to be able to incorporate them into the discourse and practice of educators, which will allow the construction of an autonomous domain for pedagogy, which provides a coherent set of strategies and approaches from which information, teaching, learning, and education processes are systematically explained (Huerta, 2007). Because they play a fundamental role for the student in building new knowledge, and for the teacher who is in charge of developing and executing a lesson plan, that can get their teaching to go outside the classroom.

From a pedagogical-epistemological perspective, "pedagogical currents" could be defined as a set of concepts, procedures, methods, precepts, school and group organizations, conceptualizations, teaching materials, educational legislation, etc. that shape the formation and arrangement of pedagogical practices and discourses. The educational institutions (from the "graduate school" in the Comnian sense to the "virtual classrooms" of Pappert), as pedagogical strategies that today are trying to introduce in the educational system (Lopez et al., 2020) and the subjects of teaching, education and training (teacher, student, pedagogue, special educator, school doctor, etc.).

Every pedagogical current is historically constituted by a system of socially formed knowledge and thought. Current that designates movement, the conglomerate of concepts, practices with a "unification" and "organizable system" (although heterogeneity and dispersion always persist) (Gaete, 2015). The world is constantly changing and education plays a fundamental role in this, pedagogical currents have allowed us to investigate, know every change that education has given, throughout history, and have allowed humanity to make analyses that seek to bring it to changes and the improvement of teaching practice.

The human being is the fact of his improvement and experience accumulated by humanity is allowed to carry out the productive activity, work, the improvement of instruments and the same are clear examples of the development and intellectual capacities their ethical-moral part that allow their development within society. Teaching is a social practice, in which subjects participate and characterize awareness and self-awareness about what it is about (Fajardo et al., 2017).

The research carried out to date has shown, that the work of contemporary theories can rehabilitate the current teaching since it maintains a solution for the recruitment and adaptation of each student in the acquisition of knowledge, which allows creating competent students capable of demonstrating for themselves that contemporary paradigm is essential for their school development.

\section{Conclusion}

In the construction of learning contemporary theories, fused to the modern school has allowed the expansion of knowledge by adapting techniques and strategies in students, and Ecuador has been involved in the application of contemporary techniques to develop new and diverse pedagogical processes. Teachers should be trained and prepared in modern techniques and educational paradigms, which will allow them to evaluate and update outdated pedagogical processes, considering that each student is a different environment.

\section{Conflict of interest statement}

The authors declared that they have no competing interests.

\section{Statement of authorship}

The authors have a responsibility for the conception and design of the study. The authors have approved the final article.

Acknowledgments

We are grateful to two anonymous reviewers for their valuable comments on the earlier version of this paper.

Vélez, M. G. B., \& Sandoval, E. M. F. (2020). Contemporaneous theory in education. International Research Journal of Management, IT and Social Sciences, 7(3), 50-57. https://doi.org/10.21744/irjmis.v7n3.890 


\section{References}

Bailey, C. J., \& Card, K. A. (2009). Effective pedagogical practices for online teaching: Perception of experienced instructors. The Internet and Higher Education, 12(3-4), 152-155. https://doi.org/10.1016/j.iheduc.2009.08.002

Cantero, D. S. (2013). Informed theory and Atlas.ti: methodological resources for educational research. Scielo, 16(1), 15.

Diaz, J. (2019). Technology, Meta-Technology And Education.

Diaz, J. y. (2013). A look at theories and pedagogical currents. (P. version, Ed.) National Collegiate of cultural educational development and professional supervision.

Dominguez, M. (2008). Determining factors in human resources management in service companies that systematically incorporate new technologies A case study in the Valencian community. Thought \& Management, $24,88-131$.

Dominguez, R. (2014). New Technologies and Education in the 21st Century. Etic@net, 4.

Dominguez, R. (2014). New technologies and education of the 21 st century. Grenada.

Dominguez, R. (2014). New technologies and education of the 21st century. (4), 13.

Fajardo, Z. E., Garcés, N. G., \& Martínez, E. F. (2017). Incidence of pedagogical currents in the learning of the contents of. Scientific Journal of Research and Knowledge, 1(4), 657-680.

Fierro, M. (2011). The Conceptual Development of Cognitive Science. Part I. Colombian Journal of Psychiatry, 40 (3), 519-533.

Gaete, M. (2015). Didactics, temporality and teacher training. Brazilian Magazine of Education, 20(62), $595-617$. https://doi.org/10.1590/S1413-24782015206203

Ghasemi, B., \& Hashemi, M. (2011). ICT: New wave in English language learning/teaching. Procedia-social and behavioral sciences, 15, 3098-3102. https://doi.org/10.1016/j.sbspro.2011.04.252

Govindasamy, T. (2001). Successful implementation of e-learning: Pedagogical considerations. The internet and higher education, 4(3-4), 287-299. https://doi.org/10.1016/S1096-7516(01)00071-9

Grouper, C., Olmedo, R., \& Rodriguez, M. (2020). The musical intelligence as a basic competition in parvular teacher. International Journal of Psychosocial Rehabilitation, $24(4), \quad 352-360$. https://doi.org/10.37200/IJPR/V24I4/PR201014

Guzmán, A., \& Martinez, O. (2018). Educational Theory from the Complexity Paradigm to Form Critical and Complex Thinking. Scientific Magazine, 3(9), 257-274.

Hashemi, M., \& Ghasemi, B. (2011). RETRACTED: Retraction notice to using mobile phones in language learning/teaching [SBSPRO 15C (2011) 2947-2951]. https://doi.org/10.1016/j.sbspro.2011.04.220

Huerta, H.C. (2007). Contemporary Pedagogical Currents. Odysseus electronic journal of pedagogy,05-23.

John, J., Thampuran, A. L., \& Premlet, B. (2016). Objective and subjective evaluation of acoustic comfort in classrooms: A comparative investigation of vernacular and modern school classroom in Kerala. Applied Acoustics, 104, 33-41. https://doi.org/10.1016/j.apacoust.2015.09.017

Kartal, T., Ozturk, N., \& Ekici, G. (2012). Developing pedagogical content knowledge in preservice science teachers through microteaching lesson study. Procedia-Social and Behavioral Sciences, 46, $2753-2758$. https://doi.org/10.1016/j.sbspro.2012.05.560

Loncar, M., Barrett, N. E., \& Liu, G. Z. (2014). Towards the refinement of forum and asynchronous online discussion in educational contexts worldwide: Trends and investigative approaches within a dominant research paradigm. Computers \& Education, 73, 93-110. https://doi.org/10.1016/j.compedu.2013.12.007

Lopez, M., Vegas, H., \& Rodriguez, M. (2020). Project-based Learning Strategy: An Innovative Proposal for Local Education System. International Journal of Psychosocial Rehabilitation, 20(1), 1666-1681. https://doi.org/10.37200/IJPR/V24I1/PR200267

Martinez, N. (2015). The positivist paradigm and the dialectical conception of knowledge. Digital Magazine , 4(2), 5.

Meneses, I., Moya, M., \& Rodríguez, M. (2020). Influence of Videogames on Student Behavior. International Journal of Psychosocial Rehabilitation, 24(1), 1692-1703. https://doi.org/10.37200/IJPR/V24I1/PR200269

Mero, C. M. M., \& Martinez, M. E. M. (2020). Importance of brain knowing for receiving information. International journal of social sciences, 3(1), 7-12. https://doi.org/10.31295/ijss.v3n1.100

National Technical-Pedagogical Council. (2013). A Look at the Currents and Theorias Pedagogicas (Vol. 1).

Riera, L., Sansevero, I., \& Lúquez, P. (2009). Environmental education: a pedagogical and scientific challenge for teachers in basic education. Laurus, 15 (30), 392-406.

Rodriguez, G. (2016). Learning theorias. Puerto La Cruz.

Salas-Velasco, M. (2007). The transition from higher education to employment in Europe: the analysis of the time to obtain the first job. Higher Education, 54(3), 333-360. https://doi.org/10.1007/s10734-006-9000-1 
Sanchez, P. K. M., Lopez, C. G. N., Lopez, M. M. L., \& Figueroa, Y. G. M. (2019). Learning problems: pedagogical intervention. International Research Journal of Engineering, IT \& Scientific Research, 5(6), 25-32. https://doi.org/10.21744/irjeis.v5n6.806

Schunk, D. (2012). Learning theories an educational perspective.

Shulman, L. S. (2000). Teacher development: Roles of domain expertise and pedagogical knowledge. Journal of applied developmental psychology, 21(1), 129-135. https://doi.org/10.1016/S0193-3973(99)00057-X

Suarez, S. L. (2000). Does business learn?: Tax breaks, uncertainty, and political strategies. University of Michigan Press.

Suryasa, W., Zambrano, J., Mendoza, J., Moya, M., \& Rodriguez, M. (2020). Mobile devices on teaching-learning process for high school level. International Journal of Psychosocial Rehabilitation, 24(4). https://doi.org/10.37200/IJPR/V24I4/PR201012

Tamir, P. (1988). Subject matter and related pedagogical knowledge in teacher education. Teaching and teacher education, 4(2), 99-110. https://doi.org/10.1016/0742-051X(88)90011-X

Tomozii, S. E., \& Topală, I. (2014). Why do we need to change the educational paradigms?. Procedia-Social and Behavioral Sciences, 142, 586-591. https://doi.org/10.1016/j.sbspro.2014.07.670

Trujillo, L. (2017). Contemporary pedagogical theorias (1 ed.). Bogota, Bogota, Colombia : Areandino.

Villalobos, J. (07 2000). Education And Awareness: Legacies Of Paulo Freire's Thought And Action. (J. Villalobos, Ed.) 4(10).

Vélez, M. G. B., \& Sandoval, E. M. F. (2020). Contemporaneous theory in education. International Research Journal of Management, IT and Social Sciences, 7(3), 50-57. https://doi.org/10.21744/irjmis.v7n3.890 